TEIXEIRA COELHO

\title{
Por uma arte outra vez transcendental
}

Este texto foi apresentado inicialmente como conferência no ciclo "Corpo e Memória" promovido pelo Museu de Arte Moderna de São Paulo durante a exposicão "Panorama de Arte Brasileira 1997 em dezembro desse ano

Por determinação do autor foi mantida a diagramação original.

\section{As reduções da arte}

Por que o diretor do Metropolitan Museum de Nova York não gosta de arte contemporânea

O que, da arte contemporânea, levar para o século XXI
Pode-se apreender o sentido anafórico de redução, como aqui empregada, a partir da noção de redução em química I processo de diminuição do número de cargas positivas do ín), em música (arranjo para um único instrumento a partir de uma partitura para vários instrumentos), fotografia lacentuação dos contrastes de uma chapa, com ênfase, numa foto b\&p, para o branco e o preto), em taquigrafia (eliminação de vogais e uso de abreviaturas com o objetivo de dar mais rapidez à escrita) e, também, do sentido comum da palavra redução, que significa "ato ou efeito de subjugar"
1. A arte passou, nos últimos cinco séculos, por uma seqüência de reduções (1) ontológicas.

Primeira, na série, a redução ontológica da figuração (o que é representado numa obra de arte, seu significado, seu interpretante) para o objeto que suporta a figuração (ou que suportava a figuração, uma vez que freqüentemente a opção pelo objeto simplesmente exclui a figuração).

O surrealismo promoveu essa redução ao defender a prática do objet trouvé, o objeto achado: qualquer objeto ou coisa (uma concha encontrada num passeio pela orla marítima) poderia ser uma obra de arte. O readymade de Duchamp é, quase sempre, um objet trouvé composé, por ter sofrido arranjos, recebido um toque do autor que lhe modificou de algum modo a aparência original. A teoria surrealista autorizava o artista (ou o achante, o encontrador, o descobridor) a expor o objet trouvé, em galeria ou salão, na qualidade de obra de arte.

A simples retirada do objeto do local em que foi encontrado e sua transferência para um lugar artístico (ateliê, galeria, museu) já implicam, por si sós, numa composição, numa redução ontológica.

Grande parcela da arte contemporânea ainda faz sucesso (de crítica) (aparentemente) em cima desta redução.

Quando Regina Silveira, numa das Bienais de São Paulo, pintou no chão a sombra anamórfica da ausente Roda de Bicicleta Enfiada numa Banqueta, de Duchamp, ela exercitou a contra-redução (a contra-desconstrução) do objeto para a figuração. 
Figuração não significa, necessariamente, figurativo, presença da figura humana e das coisas reconhecíveis "tais como são". Figura é aquilo que, além de deixar ver alguma coisa, não precisa ser vista para conseguir veicular algo que o espectador pode ver. No Boi Escorchado de Rembrandt há figuração por existir, ali, algo que se deixa ver através de uma forma visível (a carcaça do boi, um rosto que espreita) e algo que não se deixa ver e no entanto é apreensível imaterialmente pelo espectador através da forma visível. Há transporte de uma dimensão para outra. Como numa tela de Francis Bacon, vejo o que está ali e vejo o que não é visível e no entanto está ali.

Nesse movimento de redução, o objeto foi em seguida (e quase de imediato) negado ele mesmo, como o fez a arte povera (arte do precário, arte da ruína, arte dos limites imanentes assumidos), que justificou variada incompetência e ausência de profissionalismo artístico: degradado, contestado, o objeto foi impedido de assumir aquilo que a redução lhe reservava. No Japão o objeto é habitualmente respeitado em sua integridade formal e ontológica (pelo artista com senso de profissionalismo). Claro, no Japão há uma tradição objetual.

A forma (a forma plenamente elaborada, a forma construída) pode resgatar o objeto e dar-lhe uma figura (como no design).

2. Segunda regressão ontológica: da obra de arte para seu autor, ou do objeto para seu autor, para seu achante.

Body art, exemplo radical dessa operação.

\author{
Passou-se do ideal (a figuração) para aquele que deseja(va) o \\ ideal.
}

E não "do ideal para aquele que precisa(va) do ideal", como anotou Nietzsche: a arte (como o ideal) não é uma necessidade, ao contrário do que defendiam E. Fischer, Mario Pedrosa (2): o que comanda a arte (e o ideal) é o desejo. O desejo não é inevitável, não é um destino.

Um universo separa o ideal de quem o deseja - um abismo, no qual apenas os românticos não acreditavam.

3. Em outra redução (não necessariamente subseqüente), do autor da obra - do corpo do autor da obra - passou-se para a mente do autor da obra: um ciclo se fecha (a serpente penetra sua boca com o próprio rabo), no retorno (não se diga "eterno") ao primeiro daqueles cinco séculos e um de seus expoentes: da Vinci e a idéia da arte como "una cosa mentale". Necessidade Vital (Ed. da Casa do Estudante do Brasil, 1949).
}

TEIXEIRA COELHO é professor da ECA-USP e diretor do MAC-USP. É autor de, entre outros, 0 s Histéricos, em colaboração com JeanClaude Bernardet (Companhia das Letras) 
A arte conceitual é a estação por excelência desta redução ontológica. Pelo menos, a primeira arte conceitual, aquela radical, que só ocorre na cabeça do pensante (Kunst im Kopf): nem obra, nem comportamento: imaterialidade, amaterialidade, primeiridade pura (ou quase): a idéia disto ou daquilo, na mente do pensante, é a "obra".

Os conceitualistas reconheceram o desgaste do objeto e da idéia do objeto como portadores de uma obra de arte. Mas (por timidez, intimidados pela tendência da moda? ou por projeto?) não retornaram à obra: refugiaram-se no domínio da figuração subjetiva, incomunicativa (a contra-figuração). Operaram um contradesconstrucionismo inacabado. Metafísico.

4. Com a redução da figura ao objeto, tanto quanto com a deste para o autor e a do autor para o conceito, faz-se a passagem da operação metafórica para a metonímica. Do distante (metáfora: transporte, em grego) passou-se para o próximo, o imediato (a metonímia). Do que transcende para o imanente. Da idéia-além, da idéia-ali, para a idéia interior. A arte que proporciona uma viagem é outra, a arte extática é outra; na arte metonímica vigora o princípio estático: ficar no lugar (ficar no seu lugar, ficar cada um no seu lugar). A arte que era uma companhia de transporte transformou-se em craca do homem (e da mulher). (Não é o mesmo que escrever: A arte, que era uma companhia de transporte, transformou-se em craca do homem.) Essa operação de subjugação recebe o nome, apropriadamente, de redução.

Recorre-se a uma companhia de transportes quando é preciso levar muita coisa e coisa importante, para um outro lugar distante, para longe; para levar pouca coisa, e coisa sem importância, para perto, para aqui mesmo, não é preciso uma companhia de transporte.

O Vaso Sanitário Masculino ou o Porta-garrafas de Duchamp (como os cinzeiros, as sacolas de plástico et al.) oferecem-se como idéias interiores. Tal é a aposta específica dessa concepção artística.

De tão imanentes, algumas ações dessa opção estética não se dão conta de que seu sentido possível lhes preexiste metonimicamente, ali ao lado, e lhes rouba toda significação. Na última "Arte-Cidade", em São Paulo, os autores de algumas instalações produzidas no interior de um complexo industrial falido e em ruínas e que reproduziam a degradação física e social ambiente não perceberam que a poucos metros dali, à disposição do olhar do espectador, estava a degradação real, em carne e osso e cimento, na forma de sem-tetos abrigados sob um viaduto. Instalações, de tão imanentes, supérfluas. 
5. Redução, em arte, não é (necessariamente) degradação: é mudança de qualidade, alteração de ponto de vista. A redução ao objeto não gera um resultado - em princípio, em si mesmo e por si só melhor ou pior que o observável no estado anterior. Mas os três estados não são equivalentes, não têm um mesmo valor semântico, não correm pelo mesmo leito antropológico. Não são, em outras palavras, relativos - não podem ser encarados do ponto de vista de uma lógica ou filosofia relativistas.

Um novo ponto de vista pode orientar um sistema imaginal (uma sensibilidade) para uma outra direção. Não necessariamente o faz. Uma bacia imaginal, uma estrutura do imaginário, tem duração cronológica muito superior à dos movimentos estéticos; o século é sua unidade de mensuração. Vetores de uma bacia imaginal - como a psicanálise freudiana alicerçada na palavra ou o materialismo histórico - costumam ter, pelo menos na "cultura ocidental", vida média ao redor de 120, 150 anos: muito pouco. Isto significa que a mudança buscada (forçada) de um ponto de vista para outro, de uma bacia para outra, pode mostrar-se irrelevante - e de nada adianta acusar o público por não conseguir entendê-la e não querer aceitá-la. $O$ artista não é a antena da sociedade: é o propositor de uma idéia, que pode enraizar-se ou não - que, portanto, pode ser perfeitamente descartável.

Os afluentes ou vetores de uma bacia imaginal não são estanques, não deixam de comunicar-se com os que os precederam: são extensões de outros, mais remotos. O freudismo, por exemplo, suporta hoje a leitura que o apresenta como braço avançado e atualizado do romantismo xamanista.

\footnotetext{
Apenas uma pequena parte de mim é contemporânea de mim mesmo: a maior parte de mim tem 200, 500, 900 anos. Na verdade, 2.500 anos de cultura "ocidental" pouco representam no contexto imaginário do homem contemporâneo.
}

$E$ isto coloca em xeque a noção tradicional de que em arte não se pode falar em pior ou melhor (i.e., pode ser válido dizer que este movimento é pior do que aquele, que este partido estético é melhor do que aquele).

O critério de valoração não é, em última instância, interior ao sistema da arte, ao contrário do que pretende muita historiografia, em particular a estruturalista (e a historiografia dominante neste século é, essencialmente, estruturalista, i.e., imanentista, em suas várias formas). O ponto de referência final da arte está fora do sistema da arte em si, está na bacia imaginal prevalente. E, nesse caso, um ponto de vista pode responder, mais e melhor do que outro, às expectativas de determinado sistema imaginal. 
Muitos curadores e diretores de museu (a maioria, talvez) firmam compromissos antes com a história e a historiografia da arte (e com artistas) do que com a arte. (Prova: a preocupação em preencher as lacunas da coleção: a arte não tem lacunas seqüenciais e a idéia de coleção não tem sentido para a arte.) (Os museus de arte deviam chamar-se "museus de história da arte".) Nessa situação a arte dificilmente deixa de remeter-se a si mesma, dificilmente consegue sair de si mesma.

6. A operação contrária à redução não é de cômoda realização. Nem sempre permite retornar ao estado anterior: uma vez ampliada, quer dizer, explodida (Blow up), uma foto dificilmente é desampliável. Não raro, a matéria (o tema, o assunto, o objeto) original se transformou. Nada impede, no entanto, um retorno, se não à matéria inicial, pelo menos ao procedimento que a gerou.

7. Outra redução que se observa no domínio da arte: a redução do ponto de vista do criador para o ponto de vista do espectador. Dupla redução, esta: ontológica e epistemológica.

Nietzsche percebeu que o espectador de sua época, tomado pelo spleen baudelairiano, espectador exaurido e estressado, só respondia, esteticamente, ao brutal, ao artificial e ao idiótico (o inocente). Nietzsche pensava em Wagner ao escrever essas palavras: esse compositor daria exatamente aquilo que queriam os espectadores da época. É como se Nietzsche tivesse visto os filmes de ação atuais, exemplo Die Hard, e coisas como Forrest Gump.

Apesar de ser um pessimista clássico ("O apocalipse é inevitável, e está chegando!") - se não for um pessimista de mercado -, Baudrillard tem alguma razão quando denuncia (enquanto o venera) o simulacro, mesmo vendo-o de maneira enviesada e limitada (quer dizer, platônica e bipolarizada).

Esta redução do ponto de vista do autor para o do observador é paralela à consolidação do mercado cultural, no século XIX.

Movimento análogo ocorreu na história da arte (ou, se deveria dizer, na historiografia da arte) quando, ao final do século XIX (com Aby Warburg, sobretudo), o tema de investigação deixou de ser a obra e seu autor para materializar-se no estudo dos patronos da arte (ou do artista), seus motivos e suas atitudes. 
A ascendência do marqueteiro cultural é outro índice dessa redução. Num primeiro momento, o ponto de vista do artista era o único parâmetro. Depois, o gosto do público determinou as opções do artista (na Grécia antiga; na Renascença, com seus patronos-ditadores; o folhetim de jornal no século passado; a telenovela, agora). $\mathrm{O}$ artista elabora (cria?) orientado pelo público - e pelo produtor. Num terceiro instante, esse produtor dá as cartas. No quarto movimento, o marqueteiro diz ao produtor (que diz ao artista) o que deve fazer: em Hollywood, filmes de bilheteria (ou que a isso aspiram) são mostrados por marqueteiros, antes do lançamento, para platéiascobaias, cujas reações ditam a eventual refação do filme.

Nietzsche poderia ter notado que não apenas o espectador quer o brutal, o artificial e o idiótico: também os quer muito criador, quando não consegue identificar o que o distingue do espectador, quando se consola ou se compraz em permanecer na esfera da vida em vez de optar pela do mundo.

\footnotetext{
O autor não se confunde com o espectador; o autor como espectador é muito diverso do autor-criador: está muito aquém (não entende necessariamente o que criou) e muito além do espectador (pôde criar).
}

8. Na base dessa redução, um equívoco (generoso apenas na aparência): aproximar o homem do belo. O ser humano não quer aproximar-se do belo. Diante de uma obra de arte, o ser humano quer tornar-se, ele, uma obra-prima (Nietzsche). Não pode fazê-lo se não recorrer a uma mediação. Mediação é distanciamento (não cofusão imediata) e, neste caso, celebração. O ser humano celebra a obra que lhe permite mutar-se em obra-prima. E celebra apenas o que lhe permite celebrar-se a si mesmo.

\footnotetext{
Para tanto, a operação de metáfora - a transcendência - é fundamental.

Nada é feio, só o homem degenerado o é. Os nazistas projetavam na arte "degenerada" sua própria degeneração ética e imaginal. Nunca poderiam transformar-se em obras-primas. Nada os impedia de fazê-lo - a não ser eles mesmos. Por isso, propuseram uma arte como eles imanente: a realista-celebratória, a realista-nazista (associações com o realismo socialista não são indevidas).

A redução do artista ao espectador é estéril. $E$ inútil. O que talvez importe seja a contra-redução do espectador ao criador.
} 
Em todo caso, o espectador dispensa o autor para transformar-se em obra-prima - motivo pelo qual a redução ao autor é irrelevante.

9. Por ter a arte contemporânea como meta (não raro inconsciente) a redução ao espectador foi que se operou a redução da obra ao objeto, depois ao autor e depois ao conceito.

10. O espectador wagneriano fascinado pelo brutal, pelo artificial e pelo idiótico (o inocente) é um ser pesado. Mas a viagem exige a eliminação do peso desnecessário. Italo Calvino havia lido Nietzsche antes de escrever a primeira de suas Lezioni Americani? "O bom é fácil, tudo que for divino tem passos ligeiros" (Nietzsche).

Nietzsche poderia ter pensado em Mozart. Woody Allen tem passos ligeiros (Todos dizem eu te amo, Annie Hall). E Fellini. Apesar de eventuais aparências, Joyce. E G. Rosa.

\section{O homem é sempre atraído pelo belo (Nietzsche).}

12. O belo é uma promessa de felicidade (Stendhal). A promessa de felicidade é permitir ao espectador transformar-se em obra-prima diante da obra de arte: Tom Jobim. E Francis Bacon. Algum Picasso. Matisse. Monet. Rubens, Michelangelo, Rodin. Turner, C. G. Friedrich. Balthus, Francis Bacon. Edward Hopper.

Transformar-se em obra-prima é muito mais do que brincar com a arte, tocá-la com as mãos (ocasional passo do processo, não o processo todo). Isto significa que instalações imanentes são irrelevantes; videoarte, em geral simulacros; animais mortos, brutal - e uma grande parte, simplesmente, inocente (ou idiótico).

É difícil transformar-se em obra de arte diante de um monte de lixo.

13. O transcendental, a felicidade, o espectador como obra-prima não dependem obrigatoriamente de uma estética do conteúdo, como exigiram a Igreja, depois o materialismo histórico em sua versão realista-socialista, depois o nazismo e o fascismo. O truque não está em acreditar num conteúdo, o truque está em acreditar na arte não-reduzida e não-redutora, na arte que não afunda com o peso do imanente e do imediato, que não se esfuma na invisibilidade e que não se autoconsome em questão de horas. 
14. Se o artista (plástico) não acreditar outra vez na arte, Robert Musil (3) terá razão ao insistir na anedota sobre o que seu bisneto poderia um dia perguntar-lhe: "Bivô, no seu tempo ainda existiam artistas [plásticos], o que é isso?"

Acreditar na arte não tem a ver com o suporte da arte (se é pintura ou não); tem a ver com uma atitude diante da arte.

Três atitudes básicas diante da arte, hoje: a arte como arte, a arte como ilustração visual, a arte como charge (charge como a charge de jornal; o artista como um chargista) (nesta última modalidade, muita instalação objetual).

Godard acredita em seu cinema - que é transcendental. G. Rosa, Drummond, Euclides da Cunha acreditavam em sua literatura, em sua poesia - que eram transcendentais.

15. Por acreditar na redução do ponto de vista do autor para o do espectador, e por supor (erroneamente) que o espectador contemporâneo não acredita mais na arte, muito artista deixou de acreditar na arte - a arte contemporânea está lotada de exemplos dessa demissão.

16. Como muito artista não acredita mais na arte, muito espectador acredita que a arte não tem mais nada a lhe dizer: só a diverti-lo. A arte o diverte, e está bem assim. A arte, porém, tem ainda muita coisa a ensinar ao espectador (Nietzsche) - se o autor assumir o papel.

17. Para estudar a temperatura, físicos operam uma redução da termodinâmica para a mecânica estatística, de modo que a temperatura de um gás seja explicada em termos da energia cinética das moléculas que o constituem. Assim procedendo, esses físicos não negam a existência da temperatura: dizem algo a respeito da temperatura e portanto pressupõem sua existência.

As reduções da arte de igual modo pressupõem, é verdade, a existência da arte, sobre a qual dizem alguma coisa. Mas a redução implica uma alteração do ponto de vista: no caso da física, de um ponto de vista macroscópico (o da termodinânica) passa-se a um ponto de vista microscópico (o da mecânica estatística). Alteração análoga de pontos de vista ocorre nas reduções da arte. Grande parte da arte contemporânea (a do objeto, do corpo, do conceito, do

"A Culture Question", in Posthumous Papers of a Living Author, Penguin, s.d. Musil es creve "poetas", não "artistas", mas a questão permanece mesma. 
espectador) é inspirada por uma estética microscópica, por uma mecânica. Será arte, ainda. Mas numa escala irrelevante para a dimensão da vida. E, talvez, do mundo.

E uma vez feita a redução do macro para o micro, a operação inversa não está assegurada.

18. Cultura é a regra; arte, a exceção (Godard). No sistema da arte contemporânea, a maior parte é cultura (redução da arte); pequena parte, arte. Essa distinção ainda é fundamental. A cada um, suas opções. 